\title{
Gut microbiota relieves inflammation in the substantia nigra of chronic Parkinson's disease by protecting the function of dopamine neurons
}

\author{
TIAN ZHANG ${ }^{1-3}$, TAN WANG ${ }^{2}$, XINXU CHEN $^{2}$, ZHENQIANG ZHAO ${ }^{2}$ and ZHIBIN CHEN ${ }^{1-3}$ \\ ${ }^{1}$ Department of Clinical Medicine, Nanjing Medical University, Nanjing, Jiangsu $211166 ;{ }^{2}$ Department of Neurology, \\ The First Affiliated Hospital of Hainan Medical University, Haikou, Hainan 570102; ${ }^{3}$ Key Laboratory of Brain Science \\ Research and Transformation in Tropical Environment of Hainan Province, Haikou, Hainan 571199, P.R. China
}

Received June 23, 2021; Accepted September 7, 2021

DOI: $10.3892 /$ etm.2021.10974

\begin{abstract}
The composition of the intestinal flora of patients with Parkinson's disease (PD) can change. However, whether reshaping the gut microbial composition can treat PD remains to be seen. The present study evaluated the effect of intestinal flora in the treatment of PD in a C57BL/6 mouse PD model induced by 1-methyl-4-phenyl-1,2,3,6-tetrahydropyridine (MPTP). Chronic, low-dose, MPTP-treated mice exhibited upregulated gene expression levels of TNF- $\alpha$ and IL-1 $\beta$ in the substantia nigra (SN) of the mice, and induced intestinal microbial disorders. This indicated that the chronic low-dose MPTP model could be used to evaluate the progress of early intestinal pathology and intestinal flora imbalance in PD. After transplantation of faecal bacteria to MPTP-induced PD mice, the level of inflammation in the SN of the mice was reduced, and motor dysfunction was alleviated. Notably, faecal microbiota transplantation (FMT) upregulated the abundance of Blautia but downregulated Anaerostipes, Bifidobacterium, ASF356 and Ruminococcus in the gut of PD mice. In addition, FMT reduced the activation of microglia and astrocytes in the $\mathrm{SN}$ and reduced the expression levels of GSK $3 \beta$, IL-1 $\beta$, inducible nitric oxide synthase and phosphorylated PTEN in the SN. Overall, the present study demonstrated that gut microbial dysfunction is associated with the pathogenesis of PD, and that FMT can protect PD mice by inhibiting neuroinflammation.
\end{abstract}

\section{Introduction}

Parkinson's disease (PD) is one of the most common neurodegenerative diseases in the world $(1,2)$. Its pathogenesis is

Correspondence to: Professor Zhibin Chen, Department of Clinical Medicine, Nanjing Medical University, 101 Longmian Avenue, Jiangning, Nanjing, Jiangsu 211166, P.R. China

E-mail: chenzhibin@hainmc.edu.cn

Key words: Parkinson's disease, gut microbiota, faecal microbiota transplantation, substantia nigra characterized by the progressive loss and functional impairment of dopaminergic neurons in the substantia nigra (SN) and striatum (3-5). As the functions of dopaminergic neurons are gradually impaired, the expression level of the rate-limiting enzyme tyrosine hydroxylase (TH), which synthesizes levodopa in the SN and striatum, will decrease or even disappear (6,7). Existing therapeutic drugs, such as levodopa, can sometimes relieve the symptoms of PD, but there is currently no therapy to prevent the neurodegeneration of PD $(8,9)$. Studies have indicated that neuroinflammation is associated with the neurodegenerative diseases of PD and is accompanied by a large number of proinflammatory cytokines in the $\mathrm{SN}$, such as TNF- $\alpha$ (10) and IL-1 $\beta$ (11). Therefore, it is important to be able to treat or prevent PD to prevent the degeneration of dopaminergic neurons.

The microbiome-gut-brain axis, a hypothesis that has been proposed in previous years, indicates that there is bidirectional communication between the gut microbiota and the brain, which includes the enteric and central nervous systems (12). Studies have demonstrated that an imbalance of the gut microbiota leads to changes in the interaction between the host and microbes, including numerous neurological diseases, such as depression and PD (13-15). Clinical data have reported that the gut microbiota in patients with PD is different compared with that in healthy individuals $(16,17)$. Therefore, it might be that the gut microbiota is a potential target for PD treatment.

Faecal microbiota transplantation (FMT) is a therapy that has received increased attention in the treatment of human disease (18). Compared with prebiotics or probiotics, FMT can quickly regulate the imbalanced gut microbiota in a short amount of time. However, in the treatment of PD, FMT has not received enough attention from clinicians and, to the best of our knowledge, there is a lack of systematic research. A recent study assessed the efficacy and safety of FMT in PD, which indicated that FMT can relieve motor and non-motor symptoms with acceptable safety in PD (19). However, the potential molecular mechanism of FMT in the treatment of PD has not yet been reported.

The present study evaluated the effect of FMT on 1-methyl-4-phenyl-1,2,3,6-tetrahydropyridine (MPTP)-induced motor function through a series of behavioural tests, such as the 
pole test and open field test. At the same time, the protective effect of FMT on intestinal inflammation and SN injury in PD mice was evaluated and verified. From $16 \mathrm{~S}$ ribosomal (r)RNA sequencing analysis through the evaluation of the intestinal microbial composition of PD mice after FMT implementation, the present study explored the neuroprotective mechanism of the intestinal flora-gut-brain axis on PD, which could provide potential for reducing the pathogenesis of PD strategies.

\section{Materials and methods}

Animals and treatment. A total of 18 male C57BL/6 mice (age, 6-8 weeks; weight, 18-22 g) were purchased from Zhejiang Academy of Medical Sciences [License number: SCXK (Su) 2019-0002)]. All mice were kept at $23 \pm 2{ }^{\circ} \mathrm{C}$ with $12 \mathrm{~h}$ light/dark cycles with $55 \%$ relative humidity and access to water and food ad libitum. All experimental protocols were authorized by the Animal Ethical Committee of the First Affiliated Hospital of Hainan Medical University (approval no. D-2017027; Hainan, P.R. China). All mice except the control group were administered an intraperitoneal injection of MPTP (20 mg/kg; MilliporeSigma). After $1 \mathrm{~h}$, mice were administered an intraperitoneal injection of probenecid (250 mg/kg; MilliporeSigma), which enhances the toxic effect of MPTP. MPTP and probenecid were injected every 3.5 days for a duration of 5 weeks, and the mice were free to drink pure water. Mice in control group were given normal saline at the same volume. During the whole treatment period, changes in body weight, visible stool consistency and faecal bleeding were assessed daily. The disease activity index (DAI) was defined as the sum of the stool consistency index $(0=$ normal; $1=$ soft but still formed; $2=$ very soft; $3=$ diarrhoea $)$, faecal bleeding index $(0=$ negative hemoccult, $1=$ positive hemoccult; $2=$ blood traces in stool visible; $3=$ rectal bleeding) and body weight loss index $(0=\sim 1 \% ; 1=$ between $1-5 \% ; 2=$ between $5-10 \% ; 3=$ between $10-15 \% ; 3=>15 \%)(20)$.

Behavioural tests. To evaluate the impairment of motor function in the MPTP-induced PD mouse model, a series of behavioural tests were performed, including the rotarod (21), pole (22) and open field (23) tests.

Rotarod test. The mice underwent three consecutive trials and rested for $30 \mathrm{~min}$ after each trial. The first time was the rotating rod training. In the last two trials, the average waiting time for falling from the rotating rod was used for analysis. The parameters of the rotating tripod system include starting speed, acceleration and maximum speed ( $1 \mathrm{rpm}$, acceleration $12 \mathrm{rpm} / 2 \mathrm{sec}, 50 \mathrm{rpm}$ ).

Pole test. Each mouse was trained three times a day before the test. On the day of the test, each mouse was tested twice, and the average value was used for statistical analysis. The test was performed after the end of MPTP administration. The climbing pole was $50-\mathrm{cm}$ high, $1-\mathrm{cm}$ in diameter and had a 35-mm diameter ball at the top. During the test, the mouse was placed on the ball, the time mouse headed down was recorded as T-turn (turn time), and the time to climb to the sole was recorded as T-LA (locomotor activity time). If the mouse stayed on the ball for $>30 \mathrm{sec}$, it was guided to climb down the rod and T-turn was recorded as $30 \mathrm{sec}$.
Open field test. The square arena $(40 \times 40 \times 40 \mathrm{~cm})$ was divided into 16 equal-sized squares. Each mouse was placed in the centre of the arena, acclimatized for $5 \mathrm{~min}$ and the number of crossings and rearing were recorded. The mouse was placed into the surrounding area, and the speed of the mouse's 10 min movement track was observed and analysed.

Immunofluorescence. Mice were anaesthetised by being intraperitoneally injected with sodium pentobarbital $(100 \mathrm{mg} / \mathrm{kg})$, after which the mice were euthanised via cervical dislocation. SN samples were collected from each mouse (3 per group). The samples were embedded in $100 \%$ paraffin wax (melting point, 54-56 ${ }^{\circ}$; $5 \mathrm{ml}$; cat no. P100930; Shanghai Aladdin Biochemical Technology Co., Ltd.) at $55^{\circ} \mathrm{C}$, left at room temperature for $12 \mathrm{~h}$ and subsequently cut into $5-\mu \mathrm{m}$ sections. The resulting sections were heated at $60^{\circ} \mathrm{C}$ for $2 \mathrm{~h}$. After dewaxing with xylene (cat no. X112054; Shanghai Aladdin Biochemical Technology Co., Ltd.) for $3 \mathrm{~min}$ at room temperature and rehydration in a descending alcohol series with concentrations of 100, 95, 90, 80 and $70 \%$, the sections were blocked with $5 \%$ foetal bovine serum (cat. no. 086-150; Nanjing Wisent Biotechnology Co., Ltd.) at room temperature for $30 \mathrm{~min}$. Sections were subsequently incubated with arginase (cat. no. ab233548; Abcam; 1:2,000), ionized calcium-binding adaptor molecule 1 (Iba-1; cat. no. ab178846; Abcam; 1:2,000), inducible nitric oxide synthase (iNOS; cat. no. AF0199; Affinity Biosciences, Ltd.; 1:200) and TH (cat. no. ab137869; Abcam; 1:500) overnight at $4^{\circ} \mathrm{C}$. The sections were washed $10 \mathrm{ml}$ tris buffered saline $+1 \%$ Tween-20 (TBST) for three times and incubated with Alexa Fluor 488 conjugated-donkey Anti-Rabbit IgG H\&L secondary antibody (cat. no. ab150073; Abcam; 1:1,000) at room temperature for $30 \mathrm{~min}$. Subsequently, the samples were stained with DAPI (SouthernBiotech) at room temperature for $10 \mathrm{~min}$. The sections were sealed with glycerin and observed under a fluorescence microscope (magnification, x400; LSM710; Zeiss $\mathrm{GmbH}$ ). Image Pro Plus 7.0 (Media Cybernetics, Inc.) software was used to analyse the $\mathrm{TH}^{+}, \mathrm{iNOS}^{+}$and Arginase ${ }^{+}$cells in the immunofluorescence images. The integrated optical density (IOD) of the positive points in each of the images was recorded using the Image Pro Plus 7.0 software, and then the value of the IOD was presented in the histogram.

Western blotting. Western blotting analysis was performed as described in previous studies $(20,24)$. SN samples were obtained from each mouse (3 per group), rapidly dissected, rinsed in 1X PBS, and homogenized in ice-cold homogenization buffer (Beyotime Institute of Biotechnology). The samples were then analysed by western blotting. The proteins were collected and centrifuged at $12,000 \mathrm{x}$ g for $15 \mathrm{~min}$ at $4^{\circ} \mathrm{C}$. A BCA protein assay kit (Beyotime Institute of Biotechnology) was used to determine the protein concentration. The samples $(20 \mu \mathrm{g})$ were separated using $12 \%$ sodium dodecyl sulphate-polyacrylamide gel electrophoresis and transferred onto a nitrocellulose membrane (Bio-Rad Laboratories, Inc.). The membranes were incubated in a blocking solution containing 5\% non-fat milk in PBST with 1\% Tween at room temperature for $1.5 \mathrm{~h}$ and then incubated with the primary antibodies diluted in blocking solution individually. The primary antibodies used were arginase (cat. no. ab233548; 1:5,000; Abcam), GSK3 $\beta$ (cat. no. 21002; 1:200; Signalway Antibody LLC), IL-1 $\beta$ (cat. 
no. ab5076; 1:1,000; Abcam), iNOS (cat. no. AF0199; 1:2,000; Affinity Biosciences, Ltd.), phosphorylated (p)-PTEN (cat. no. ab109454; 1:10,000; Abcam), PTEN (cat. no. ab267787; 1:1,000; Abcam) and $\alpha-7$ nicotinic acetylcholine receptor $(\alpha 7 \mathrm{n}$ AChR; cat. no. ab216485; 1:1,000; Abcam). After incubation with the primary antibodies at $4^{\circ} \mathrm{C}$ for $12 \mathrm{~h}$, the membranes were incubated with a horseradish peroxidase-conjugated goat anti-rabbit IgG secondary antibody (cat. no. A0208; 1:10,000; Beyotime Institute of Biotechnology) for $1 \mathrm{~h}$ at room temperature. The bound antibodies were detected using a chemiluminescence system (ECL Plus, Thermo Fisher Scientific, Inc.). GAPDH was used as an internal control. Image Lab V 3.0 (Bio-Rad Laboratories, Inc.) and Quantity One v4.62 (Bio-Rad Laboratories, Inc.) software were used to quantified the immunoblotted bands.

Gut microbiota analysis. At the end of the pole test, mice were anaesthetised via intraperitoneal injection with sodium pentobarbital $(100 \mathrm{mg} / \mathrm{kg})$, and were then euthanised using cervical dislocation. The caecum content ( $0.5 \mathrm{~g}$ per sample) was quickly removed, and the gut microbiota was analysed using next gene sequencing (25). 16S rRNA gene amplification was evaluated using the Illumina MiSeq platform by a standardized experimental procedure that provided by Illumina (Illumina, Inc.) (26). Operational taxonomic units were used for Chaol $\alpha$ diversity and observed species value. The characterization of differences was assessed using the Kruskal-Wallis rank-sum test to detect features with different abundances.

$R N A$ extraction and reverse transcription-quantitative PCR $(R T-q P C R)$. After euthanasia, the colon tissues were collected immediately. Total RNA was extracted from colon/SN tissues using RNAiso Plus (cat. no. 9108; Takara Bio, Inc.) according to the manufacturer's instructions. cDNA was generated from the total RNA isolated above using a PrimeScript ${ }^{\mathrm{TM}}$ RT reagent kit with a gDNA Eraser Maxima First-Strand cDNA Synthesis kit (cat. no. RR047A; Takara Bio, Inc.) according to the manufacturer's instructions. Expression levels of target mRNAs were quantified by RT-qPCR using TB Green ${ }^{\circledR}$ Premix Ex Taq ${ }^{\mathrm{TM}}$ (cat. no. RR820A; Takara Bio, Inc.) and the following primer pairs: IL-1 $\beta$ Forward, 5'-GAAATGCCACCTTTTGACAGTG-3', and reverse, 5'-ATCTTTTGGGGTCCGTCAACT-3'; IL-10 forward, 5'-TGCTATGCTGCCTGCTCTTA-3', and reverse, 5'-TCATTTCCGATAAGGCTTGG-3'; TGF- $\beta$ forward, 5'-GCCTGAGTGGCTGTCTTTTGA-3', and reverse, 5'-GCTGAATCGAAAGCCCTGTATT-3'; TNF- $\alpha$ forward, 5'-GTGGAACTGGCAGAAGAG-3', and reverse, 5'-AATGAGAAGAGGCTGAGAC-3'; allograft inflammatory factor 1 (Iba1) forward, 5'-CAGACTGCCAGCCTAAGACA-3', and reverse, 5'-AGGAATTGCTTGTTGATCCC-3'; arginase forward, 5'-CTCCAAGCCAAAGTCCTTAGAG-3', and reverse, 5'-GGAGCTGTCATTAGGGACATCA-3'; GSK3 $\beta$ forward, 5'-ATGGCAGCAAGGTAACCACAG-3', and reverse, 5'-TCTCGGTTCTTAAATCGCTTGTC-3'); iNOS forward, 5'-GTTCTCAGCCCAACAATACAAGA-3', and reverse, 5'-GTGGACGGGTCGATGTCAC-3'; and GAPDH forward, 5'-CCAGTATGACTCCACTCACG-3', and reverse, 5'-GACTCCACGACATACTCAGC-3'. PCR was performed on an Step One plus (Applied Biosystems) with the following thermocycling conditions: Initial denaturation at $95^{\circ} \mathrm{C}$ for
$10 \mathrm{~min}$ followed by 40 cycles of $95^{\circ} \mathrm{C}$ for $15 \mathrm{sec}$ and $60^{\circ} \mathrm{C}$ for $60 \mathrm{sec}$. Melt curves were recorded at $95^{\circ} \mathrm{C}$ for $15 \mathrm{sec}, 72^{\circ} \mathrm{C}$ for $60 \mathrm{sec}$ and $95^{\circ} \mathrm{C}$ for $15 \mathrm{sec}$. The fold difference in expression was calculated using the $2^{-\Delta \Delta C t}$ method (27).

Transplantation of faecal microbiota. Donor male C57BL/6 $(\mathrm{n}=6$; age, 6-8 weeks; weight, 18-22 g) mice were intraperitoneally injected with sodium pentobarbital $(100 \mathrm{mg} / \mathrm{kg})$, and then euthanised using cervical dislocation. Fresh faecal pellets were collected from normal healthy mice and diluted immediately with sterile PBS (1 faecal pellet/ml). For each experiment, several faecal pellets from different mice were resuspended together in PBS. Briefly, the faeces were steeped in sterile PBS for $\sim 15 \mathrm{~min}$, shaken and then centrifuged at $1,000 \mathrm{x} \mathrm{g}$ and $4{ }^{\circ} \mathrm{C}$ for $5 \mathrm{~min}$. The suspension was centrifuged at $8,000 \mathrm{x} \mathrm{g}$ and $4^{\circ} \mathrm{C}$ for 5 min to obtain the total microbiota and then washed twice in PBS. The final microbial suspension was mixed with an equal volume of $40 \%$ sterile glycerol to a final concentration of $20 \%$ and then stored at $-80^{\circ} \mathrm{C}(28)$. After MPTP $(20 \mathrm{mg} / \mathrm{kg})$ and probenecid $(250 \mathrm{mg} / \mathrm{kg})$ were injected every 3.5 days for a duration of 5 weeks, mice were randomly divided into the following three groups: The control group, the MPTP group, and the MPTP + FMT group. For the MPTP + FMT group, $200 \mu 1 /$ day of microbial suspension $\left(10^{8} \mathrm{CFU} / \mathrm{ml}\right)$ was transplanted to gut microbiota-depleted mice for 2 weeks, and the control and MPTP groups were administered saline at a dose of $200 \mu \mathrm{l} / \mathrm{day}$.

Histopathological scoring. At the end of the experiment, colon tissues were collected and then placed into $70 \%$ ethanol at $4^{\circ} \mathrm{C}$ for $24 \mathrm{~h}$. Fixed distal colon tissues were embedded in paraffin and cut into 5-mm sections. Tissues were stained with haematoxylin and eosin (H\&E) using standard techniques as previously reported (29).

Statistical analysis. Data are presented as the mean \pm standard deviation (unless otherwise shown) of at least three experiments. Differences between experimental groups were analysed for statistical significance using one-way analysis of variance, followed by the Tukey's post hoc multiple comparison test with GraphPad Prism 7.0 software (GraphPad Software, Inc.). P<0.05 was considered to indicate a statistically significant difference.

\section{Results}

$F M T$ relieves motor dysfunction in the MPTP-induced $P D$ mouse model. MPTP is a commonly used drug to build an animal model of PD (30). In the present study, mice received intraperitoneal injections of MPTP $(20 \mathrm{mg} / \mathrm{kg})$ and probenecid $(250 \mathrm{mg} / \mathrm{kg})$ in PBS every 3.5 days. To explore the effect of MPTP on motor dysfunction, motor coordination was examined using the rotarod test, bradykinesia was measured by the pole test and motor performance was assessed by the open-field test. In the rotarod test, MPTP significantly reduced the fall-off latency compared with the control (Fig. 1A). However, FMT markedly increased the fall-off latency compared with the MPTP group (Fig. 1A). Additionally, in the pole test, the T-turn and T-LA values were both significantly increased in the MPTP group compared with the control group (Fig. 1B and C); however, these values were decreased in the MPTP + FMT group compared with the MPTP group, significantly so 
A

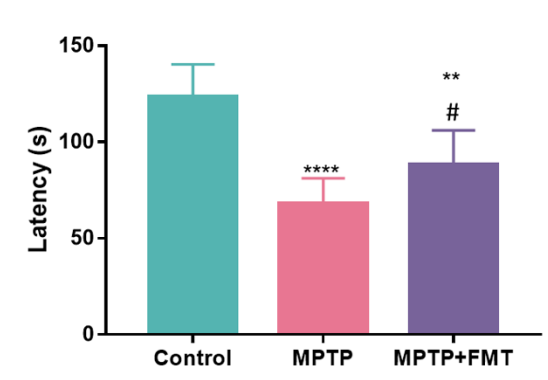

D

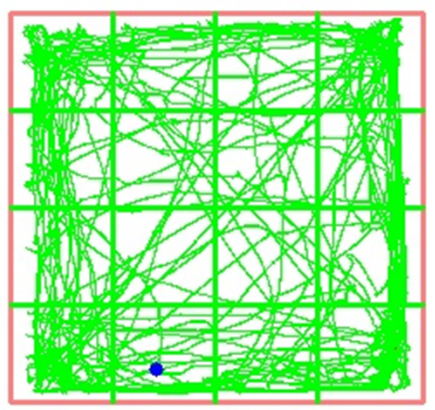

$\mathbf{E}$

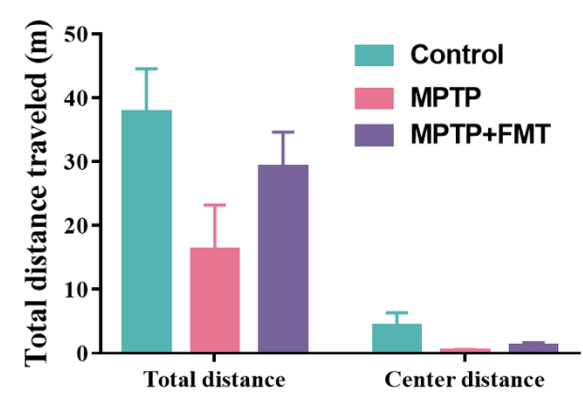

B

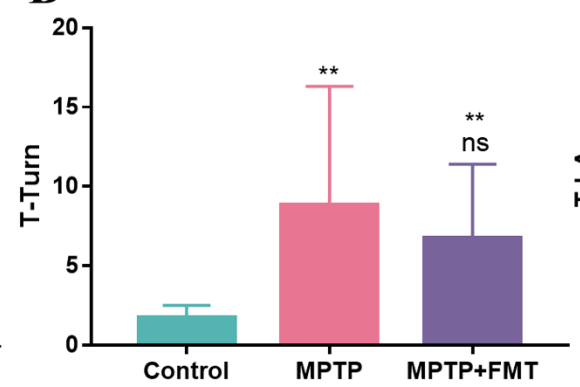

C

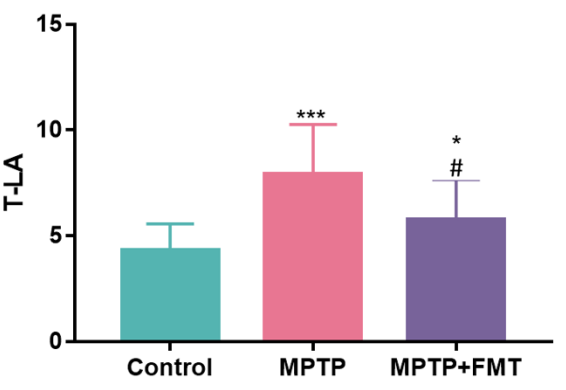

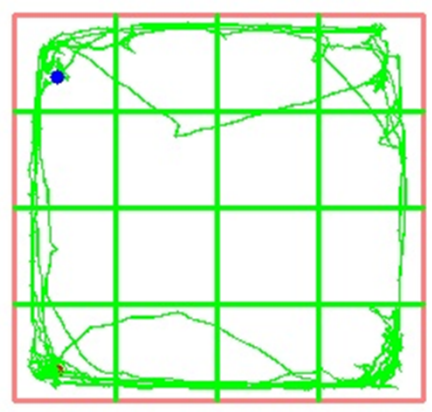

$\mathbf{F}$

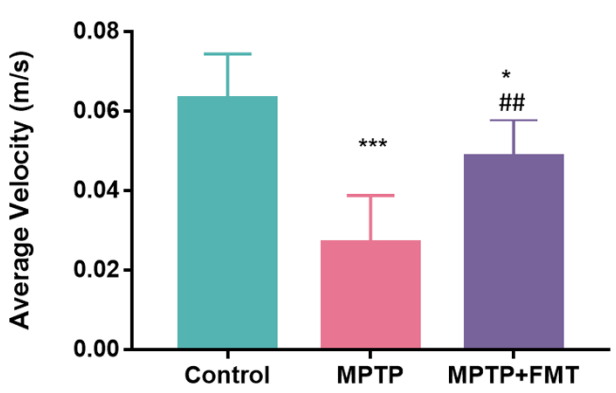

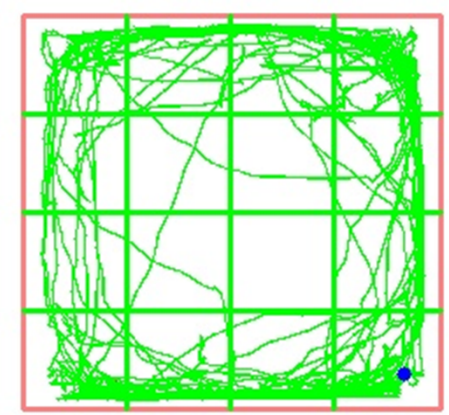

G

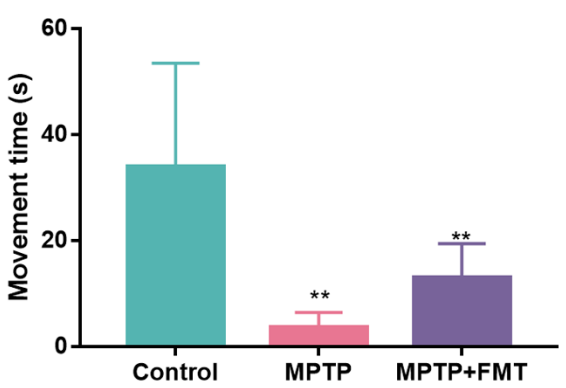

Figure 1. FMT exhibits protective effects in the MPTP-induced Parkinson's disease mouse model. (A) Fall-off latency measurement in rotarod test. (B) T-turn and (C) T-LA values in pole test. (D) Mice motion trajectory, (E) total travelled, (F) average velocity distance and (G) movement time in open field test. $\mathrm{n}=3$. ${ }^{*} \mathrm{P}<0.05,{ }^{* *} \mathrm{P}<0.01$ and ${ }^{* * *} \mathrm{P}<0.005$ and ${ }^{* * * *} \mathrm{P}<0.001$ vs. control; ${ }^{*} \mathrm{P}<0.05,{ }^{\# \#} \mathrm{P}<0.01$ vs. MPTP. ns. indicates no significance vs. MPTP. MPTP, 1-methyl-4-phenyl-1,2,3,6-tetrahydropyridine; FMT, faecal microbiota transplantation; ns., no significance; T-LA, locomotor activity time.

for T-LA. Furthermore, in the open-field test (Fig. 1D), MPTP disturbed the motor activity of mice compared with the control mice, as evidenced by a marked decrease in the total travelled distance (Fig. 1E) and a significant decrease in average velocity (Fig. 1F) and movement time (Fig. 1G). FMT protected the motor activity of mice, as evidenced by the markedly increased total travelled distance (Fig. 1E) and movement time (Fig. 1G) and the significantly increased average velocity (Fig. 1F) compared with the MPTP group mice. These results indicated that FMT might have positive effects in relieving motor dysfunction of PD.

FMT relieves chronic inflammation in the colon of the MPTP-induced PD mouse model. Whether FMT could relieve chronic inflammation in the colon of mice was next assessed, and the body weight and DAI score were recorded during the present study. The results indicated that the body weight did not show significant differences between the MPTP and control groups (Fig. 2A); however, the DAI score was increased significantly in the MPTP group (Fig. 2B). After administration of FMT, the body weight was not significantly different compared with that of the MPTP group (Fig. 2A), but the DAI score was significantly decreased in the FMT group (Fig. 2B). Moreover, the gene expression levels of IL-1 $\beta$ and IL-10 in colon tissue were analysed. The results revealed that the expression of IL-1 $\beta$ was upregulated but IL-10 was downregulated in the MPTP group compared with the control (Fig. 2C and D). FMT significantly downregulated the expression level of IL-1 $\beta$ and upregulated the gene expression level of IL-10 compared with the MPTP group (Fig. 2C and D). When the mice were sacrificed, the histological effects of MPTP were measured using H\&E staining. Mice in the MPTP group exhibited disruption of the epithelial architecture (labelled using black arrows), crypt loss (labelled using red arrows) and an increase in the number of inflammatory cells (labelled using blue arrows; Fig. 2E). FMT prevented these signs of intestinal inflammation, particularly for the crypt structure, which was relatively intact and had a low number of inflammatory cells (Fig. 2E).

FMT reconstructs the composition of gut microbiota in the MPTP-induced PD mouse model. To assess whether FMT 
A

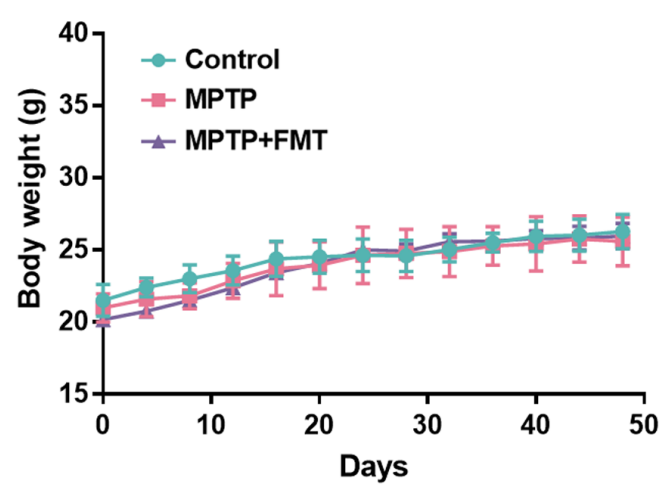

C

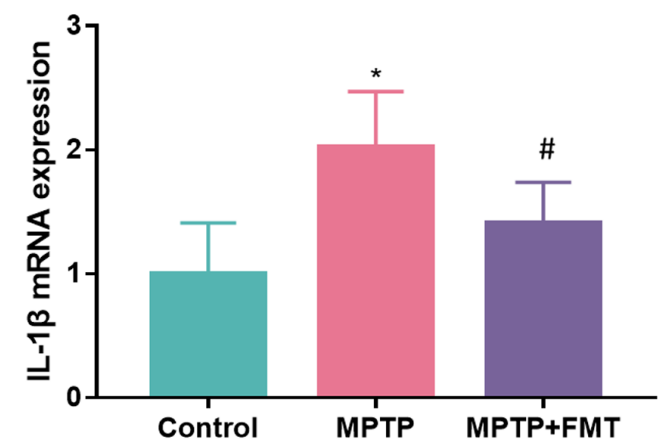

B

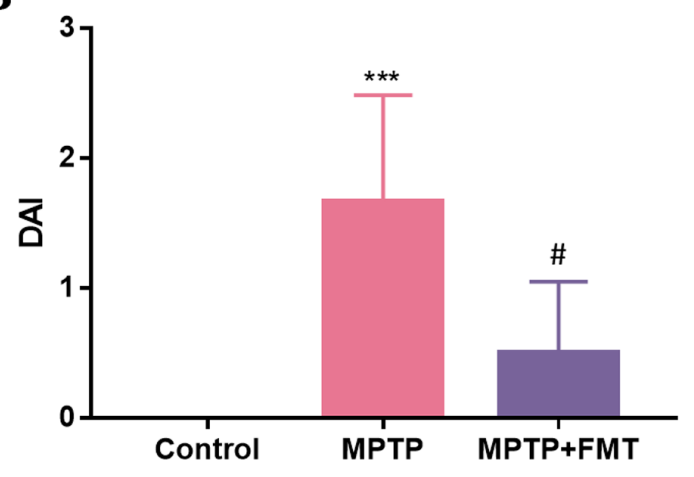

D

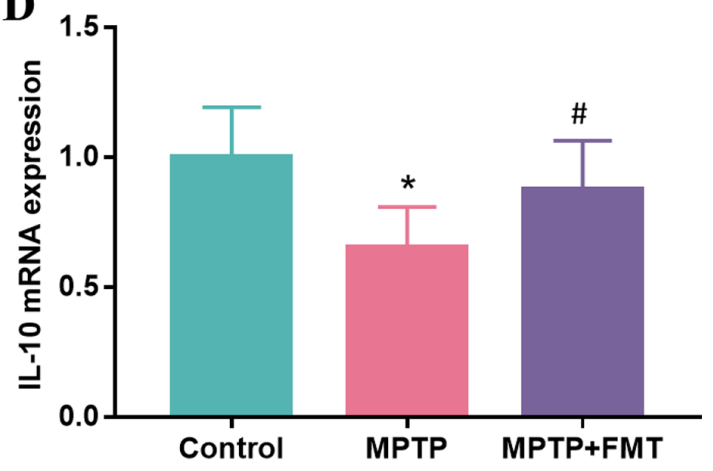

$\mathbf{E}$
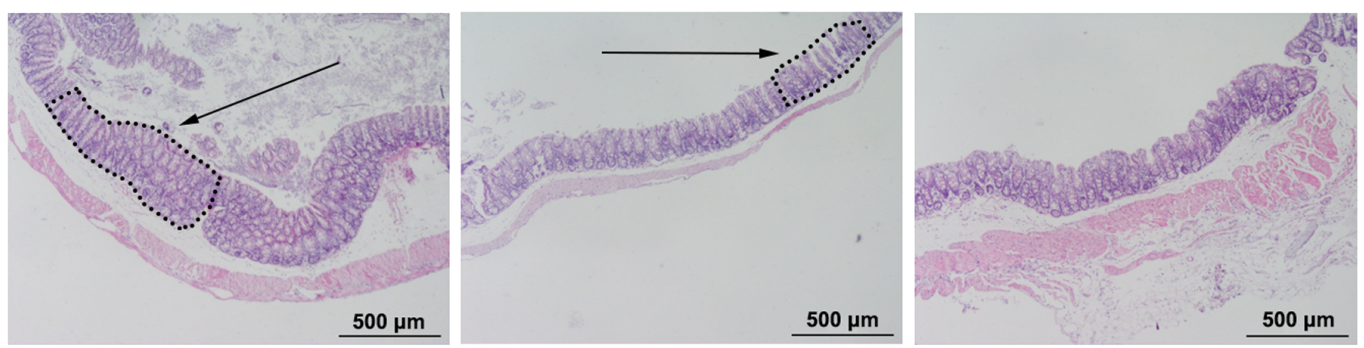

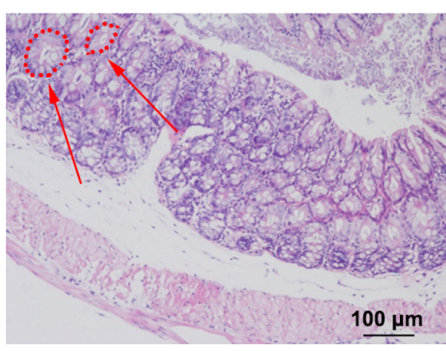

Control

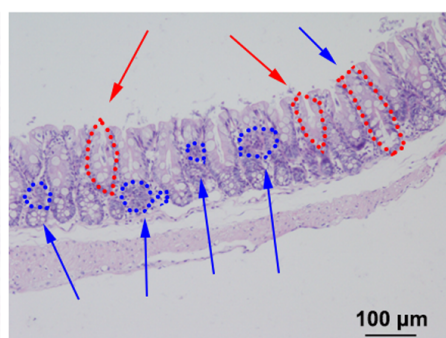

MPTP

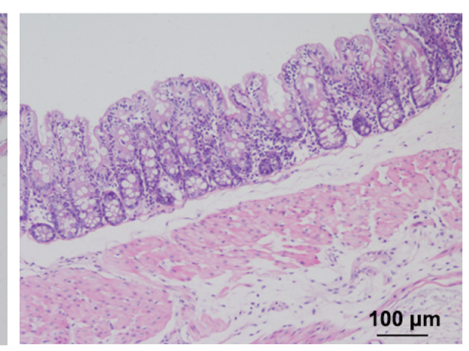

MPTP+FMT

Figure 2. FMT relieves chronic inflammation in the colon of the MPTP-induced Parkinson's disease mouse model. (A) Mice body weight, (B) DAI score, The gene expression levels of (C) IL-1 $\beta$ and (D) IL-10 in colon tissue. (E) Haematoxylin and eosin staining of mice colon tissues. Black arrow, epithelial architecture; red arrow, crypt; blue arrow, inflammatory cells. $\mathrm{n}=3$, scale bars represent $500 \mu \mathrm{m}$ and $100 \mu \mathrm{m}$, respectively. ${ }^{*} \mathrm{P}<0.05$ and ${ }^{* * * *} \mathrm{P}<0.005$ vs. control; ${ }^{\#} \mathrm{P}<0.05$ vs. MPTP. MPTP, 1-methyl-4-phenyl-1,2,3,6-tetrahydropyridine; FMT, faecal microbiota transplantation; DAI, disease activity index.

could reconstruct the compositions of gut microbiota in the MPTP-induced PD mouse model, faecal microbiota communities were profiled by next gene sequencing. Based on $16 \mathrm{~S}$ rRNA gene amplicon sequencing, as demonstrated in Fig. 3A, the composition of gut microbiota in control and MPTP groups were different. The $\alpha$ diversity for all groups represented by Chaol indexes is shown in Fig. 3B, which indicated that MPTP significantly increased the richness of gut microbiota at the phylum level. In addition, the observed species were significantly increased in the MPTP group compared with the control group (Fig. 3C). However, compared with the MPTP group, there was no significant difference in the FMT group. In further analysis, the bacterial composition of Actinobacteria, Proteobacteria and Tenericutes were significantly increased in the MPTP groups compared with that of the controls (Fig. 3D-F). Moreover, compared with the MPTP group, the bacterial composition of Proteobacteria and Tenericutes was significantly decreased (Fig. 3D and F). In addition, the gut microbiota differences 
A

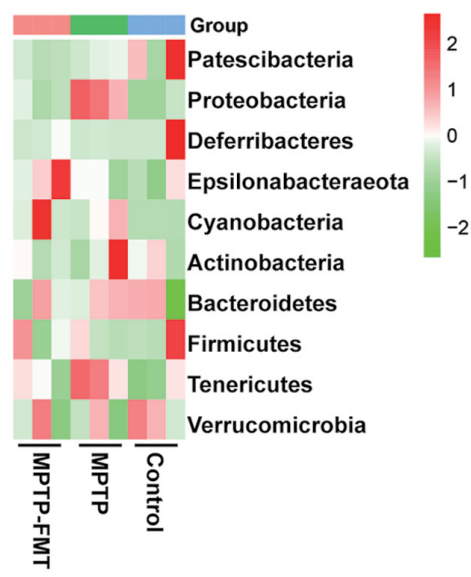

B

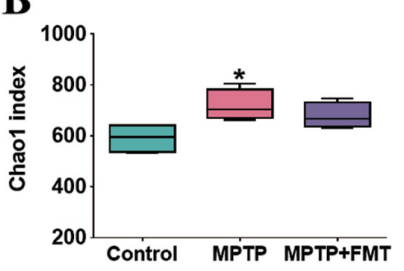

C

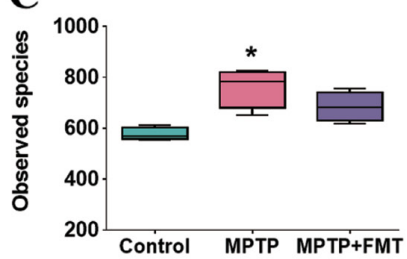

$\mathbf{F}$

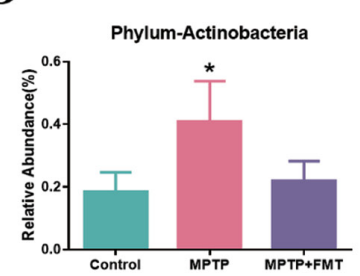

$\mathbf{E}$

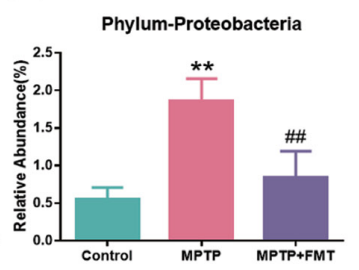

Phylum-Tenericutes

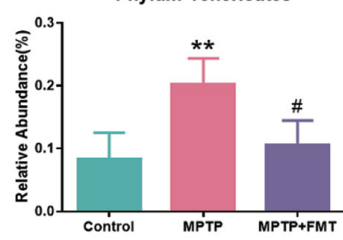

$\mathbf{G}$
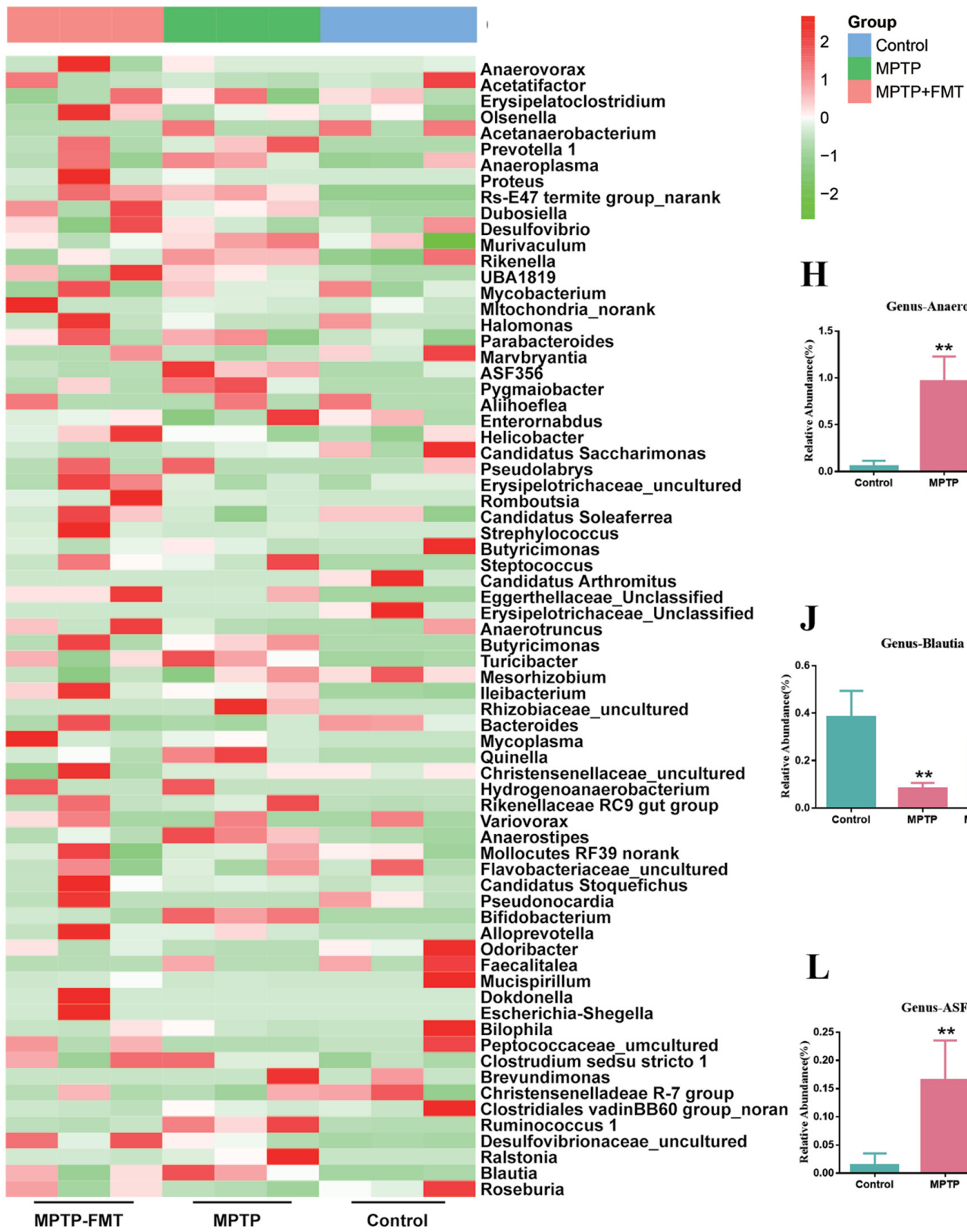

$\mathbf{H}$

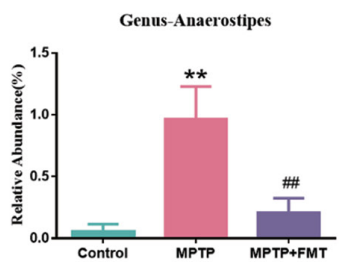

I

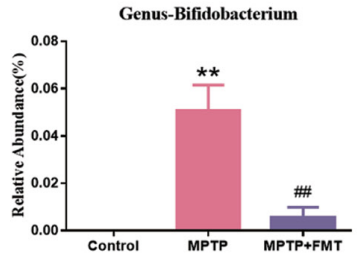

$\mathbf{J}$

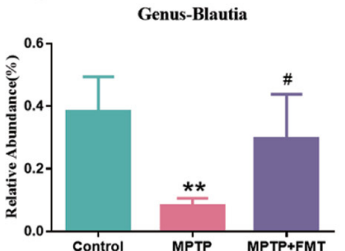

$\mathbf{L}$

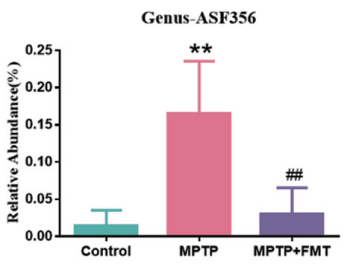

$\mathbf{K}$

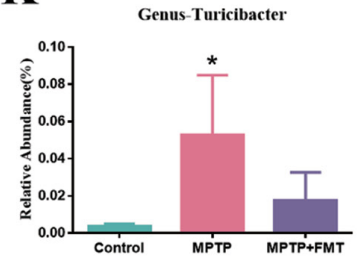

Figure 3. FMT reconstructs the compositions of gut microbiota in the MPTP-induced Parkinson's disease mouse model. (A) Heatmap of gut microbiota composition at the phylum level. Red, high expression; green, low expression. (B) Shannon index of microbiota diversity and (C) observed species. The relative abundance of bacterial of (D) Actinobacteria, (E) Proteobacteria and (F) Tenericutes at phylum level. (G) Heatmap of gut microbiota composition at genus level. The relative abundance of bacterial of (H) Anaerostipes, (I) Bifidobacterium, (J) Blautia, (K) Turicibacter, (L) ASF356 and (M) Ruminococcus. ${ }^{*} \mathrm{P}<0.05$ and ${ }^{* *} \mathrm{P}<0.01$ vs. control; ${ }^{*} \mathrm{P}<0.05$ and ${ }^{\# \#} \mathrm{P}<0.01$ vs. MPTP. MPTP, 1-methyl-4-phenyl-1,2,3,6-tetrahydropyridine; FMT, faecal microbiota transplantation. 

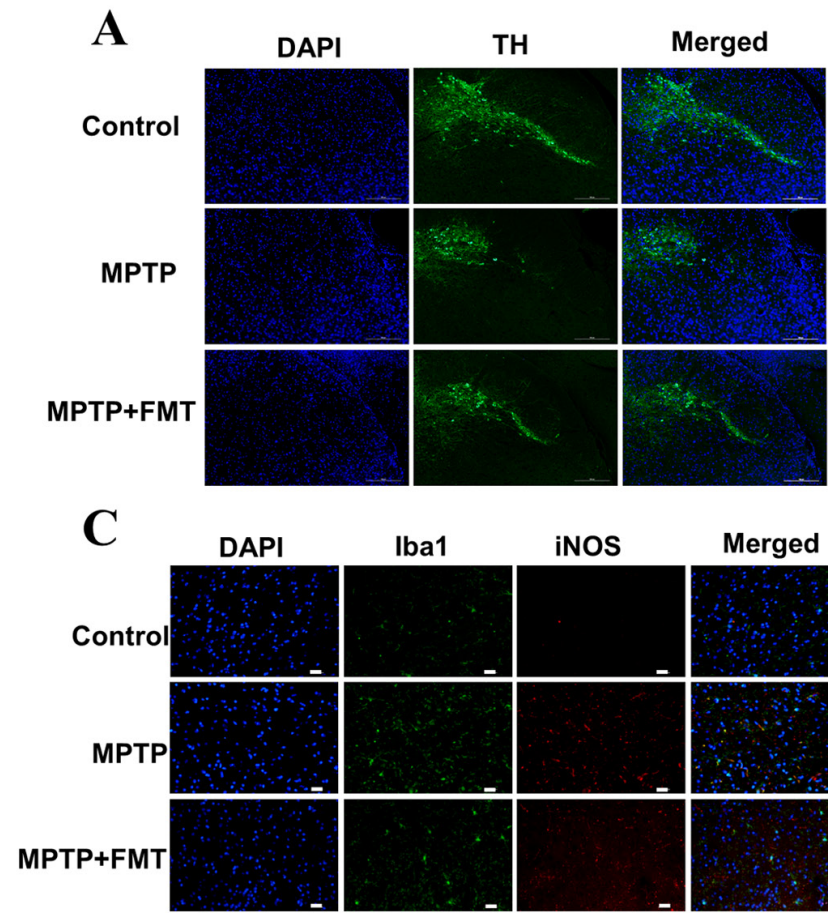

Iba1
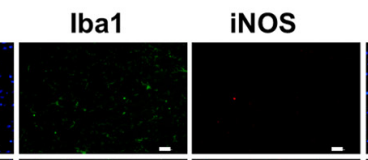

Merged
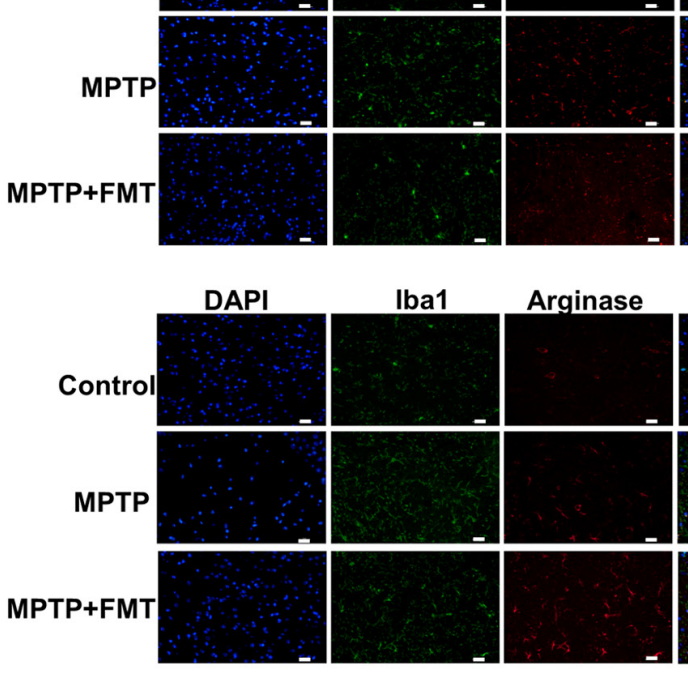
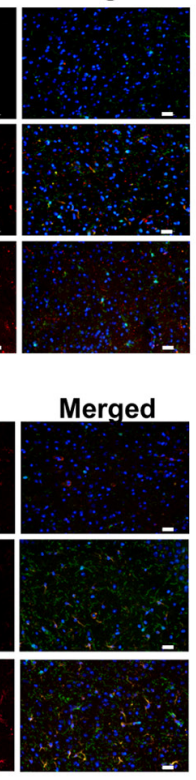

B

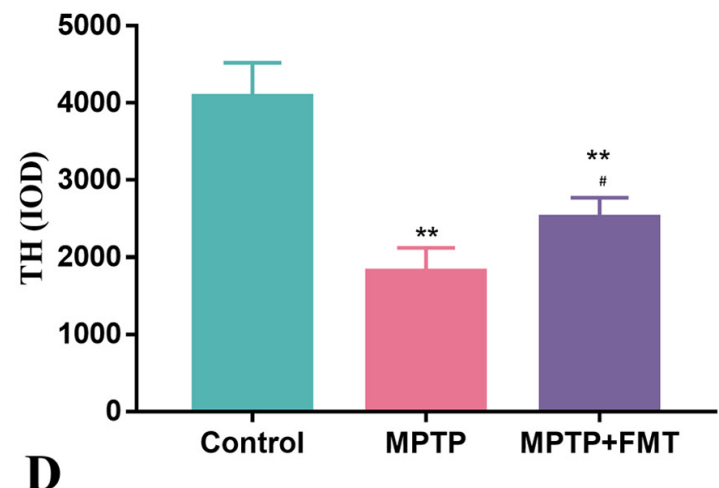

D

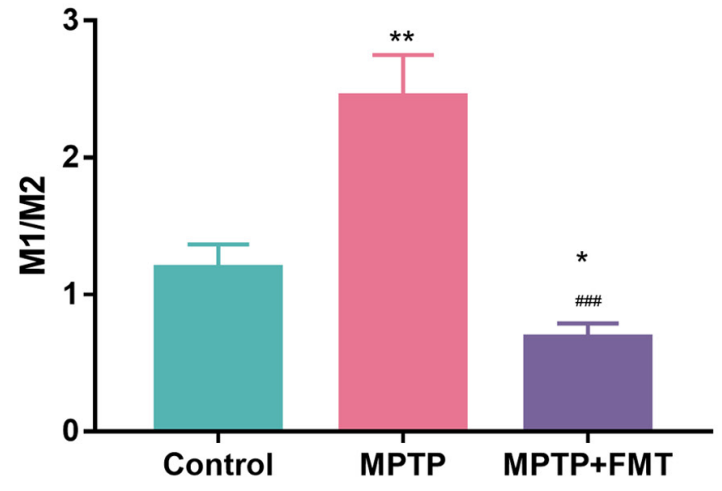

Figure 4. FMT protects against neuronal damage in an MPTP-induced Parkinson's disease mouse model. (A) Immunofluorescence analysis of the expression levels of TH and (B) subsequent quantification. (C) Immunofluorescence analysis of $\mathrm{Iba}^{+} \mathrm{iNOS}^{+}$cells (representing M1 cells) and Iba1 ${ }^{+} \mathrm{Arginase}^{+}$cells (representing M2 cells) and (D) quantified fluorescence expression analysis. $\mathrm{n}=3$. ${ }^{*} \mathrm{P}<0.05,{ }^{* *} \mathrm{P}<0.01$ vs. control; ${ }^{\#} \mathrm{P}<0.05$ and ${ }^{\# \# \#} \mathrm{P}<0.005$ vs. MPTP. MPTP, 1-methyl-4-phenyl-1,2,3,6-tetrahydropyridine; FMT, faecal microbiota transplantation; TH, tyrosine hydroxylase; Iba1, allograft inflammatory factor 1; iNOS, inducible nitric oxide synthase.

between the control and MPTP groups at the genus level are presented in Fig. 3G. The results indicated that the compositions of Anaerostipes, Bifidobacterium, Turicibacter, ASF356 and Ruminococcus were significantly increased, but Blautia was significantly decreased (Fig. 3H-M). In the FMT group, the gut microbiota compositions of Anaerostipes, Bifidobacterium, ASF356 and Ruminococcus were significantly decreased, but Blautia was significantly increased (Fig. 3H-M).

FMT protects against neuronal damage in the MPTP-induced $P D$ mouse model. To confirm the impact of FMT on the protection of the $\mathrm{SN}$, the expression levels of $\mathrm{TH}$, iNOS and arginase were measured using immunofluorescence. As presented in Fig. 4A and B, the expression levels of TH was significantly decreased. These results indicated that MPTP has a positive effect on damage to the SN. After treatment with FMT, the expression level of TH was significantly increased. In addition, the $\mathrm{Iba1}^{+} \mathrm{iNOS}^{+}$cells (representing M1 cells) and $\mathrm{Iba1}^{+}$Arginase $^{+}$cells (representing M2 cells) were analysed by immunofluorescence and are presented in Fig. 4C. The ratio of the number of positive cells per $0.1 \mathrm{~mm}^{2}$ of M1 and M2 cells are presented in Fig. 4D, which revealed that the number of M1 cells was significantly upregulated in the MPTP group compared with the control. After treatment with FMT, it was significantly downregulated compared with the MPTP and control groups. These results indicated that FMT could have a positive effect on the protection of neuronal damage.

FMT suppresses inflammation in the SN in the MPTP-induced $P D$ mouse model. To verify whether FMT could suppress inflammation in the $\mathrm{SN}$, the expression levels of inflammatory cytokines in the $\mathrm{SN}$ were detected. The protein expression levels of arginase, GSK3 $\beta$, IL-1 $\beta$, iNOS and p-PTEN were significantly upregulated in the MPTP group compared with the control (Fig. 5A-F), while the protein expression level of $\alpha 7 n$ AchR was downregulated (Fig. 5G). In the FMT group, the protein expression levels of GSK3 $\beta$, IL-1 $\beta$, iNOS and p-PTEN were significantly downregulated compared with the MPTP group (Fig. 5C-F), while the protein expression levels of $\alpha 7 n$ AchR (Fig. 5G) and arginase (Fig. 5B) were significantly upregulated. In addition, the gene expression levels of arginase, GSK3 $\beta$, IL-1 $\beta$ and iNOS were consistent with the protein levels (Fig. 5H-K). 
A

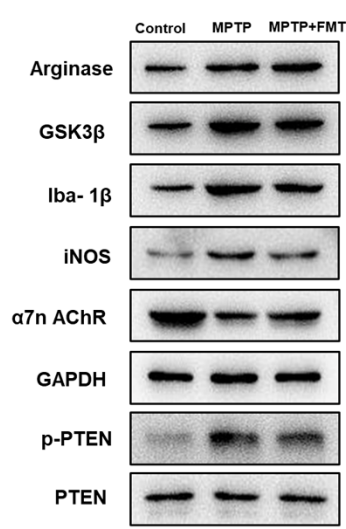

B

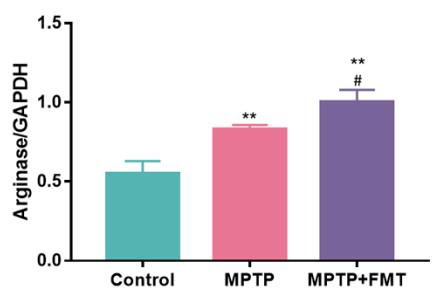

$\mathbf{E}$

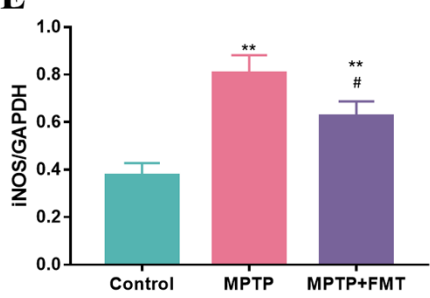

C

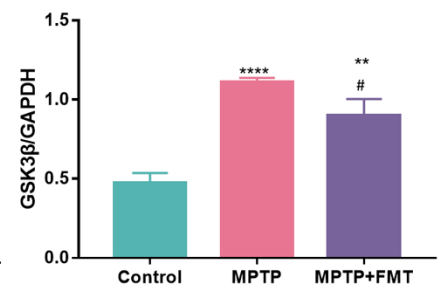

$\mathbf{F}$

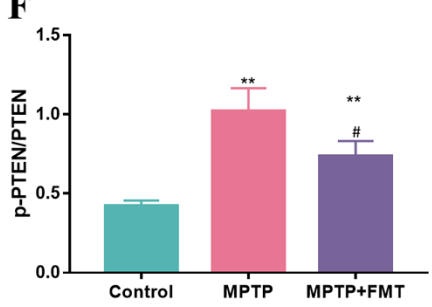

$\mathbf{J}$

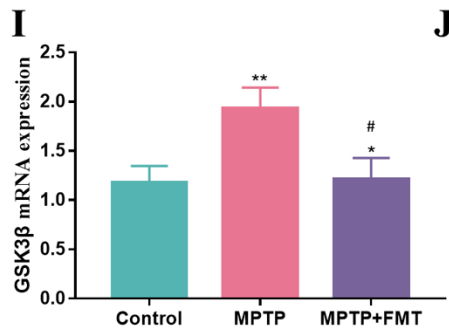

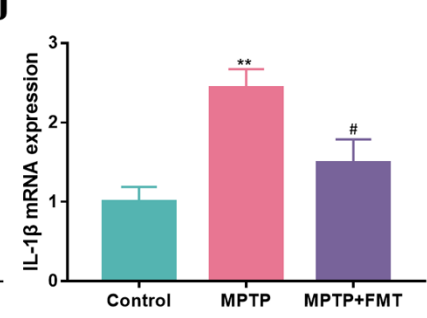

D
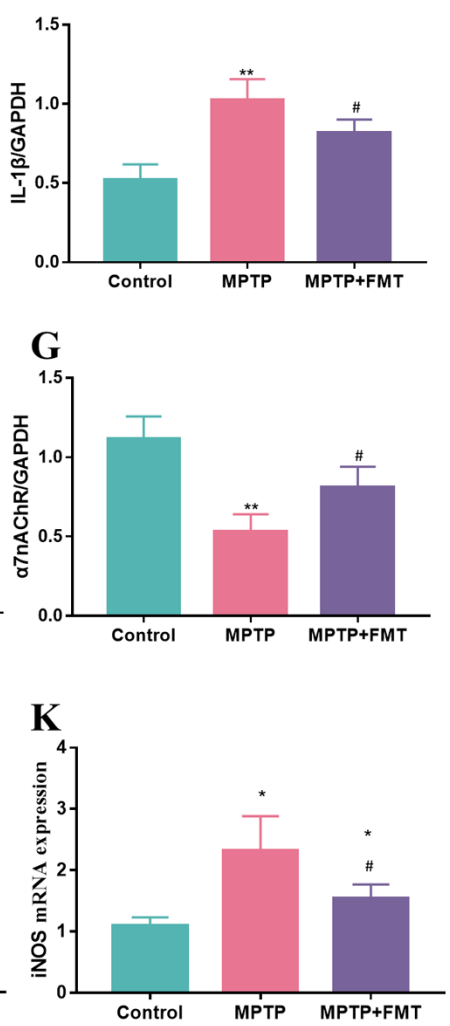

$\mathbf{N}$

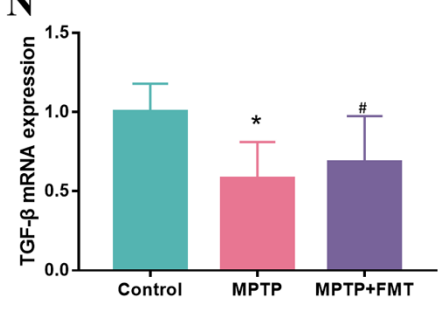

Figure 5. FMT suppresses inflammation in the substantia nigra in an MPTP-induced Parkinson's disease mouse model. (A) Western blotting bands of Arginase, GSK3 $\beta$, IL-1 $\beta$, iNOS, $\alpha 7 n$ AchR and p-PTEN. Western blotting bands statistical quantification of (B) Arginase, (C) GSK3 $\beta$, (D) IL-1 $\beta$, (E) iNOS, (F) p-PTEN and (G) $\alpha 7 n$ AchR. Gene expression levels of (H) Arginase, (I) GSK3 $\beta$, (J) IL-1 $\beta,(\mathrm{K})$ iNOS, (L) TNF- $\alpha,(\mathrm{M}) \mathrm{IL}-1 \beta$, and $(\mathrm{N}) \mathrm{TGF}-\beta$. $\mathrm{n}=3$. ${ }^{*} \mathrm{P}<0.05,{ }^{* *} \mathrm{P}<0.01$, ${ }^{* * *} \mathrm{P}<0.005$ and ${ }^{* * * *} \mathrm{P}<0.001$ vs. control; ${ }^{\#} \mathrm{P}<0.05$ and ${ }^{\# \#} \mathrm{P}<0.01$ vs. MPTP. MPTP, 1-methyl-4-phenyl-1,2,3,6-tetrahydropyridine; FMT, faecal microbiota transplantation; Iba1, allograft inflammatory factor 1; iNOS, inducible nitric oxide synthase; $\alpha 7 \mathrm{n}$ AchR, $\alpha-7$ nicotinic acetylcholine receptor; p-, phosphorylated.

Furthermore, the gene expression levels of TNF- $\alpha$ (Fig. 5L) were upregulated in the MPTP group compared with the control, but IL-10 and TGF- $\beta$ were downregulated (Fig. $5 \mathrm{M}$ and N).

\section{Discussion}

Recent studies have demonstrated that the gut microbial composition is disordered in patients with PD (31-33), and the data of the present study validated the difference in the composition of the intestinal flora in the mouse PD model. Notably, the present study revealed that the destruction of intestinal microbes in PD mice involved an increase in the phyla Actinobacteria, Proteobacteria and Tenericutes, which is consistent with the results observed in patients with $\operatorname{PD}(34,35)$. It is known that the increase in Tenericutes may be the result of intestinal inflammation (36). In particular, the abundance of Actinobacteria and Proteobacteria has been indicated to be positively correlated with the severity of postural instability and gait difficulty in PD (37). These results indicate that specific intestinal microbial disorders may be associated with the pathogenesis and clinical manifestations of PD.

The present study revealed that reducing intestinal microbial malnutrition through FMT had a protective effect on PD. FMT is a treatment method based on the relationship between the intestinal flora and the host $(19,38,39)$. It involves transplanting the intestinal microbes from healthy donors to patients with PD to reform the composition of the intestinal flora of the patients and achieve the therapeutic effect $(34,40)$. Notably, in the present study, FMT not only alleviated the dyskinesia of PD mice, but also improved the main microbial populations of PD mice, such as Anaerostipes, Bifidobacterium, ASF356 and Ruminococcus.

Results of a previous study revealed that TH is a key enzyme in the biosynthetic pathway of dopamine (DA) (41). PD is a neurodegenerative disease caused by severely insufficient DA in the SN striatum (42). Upregulated expression of TH in the $\mathrm{SN}$ has a positive effect on alleviating the symptoms of 
PD (43). The current study demonstrated that FMT treatment could increase the expression of $\mathrm{TH}$ in the $\mathrm{SN}$ of mice with PD. Microglia, which were immune cells reside in the central nervous system, are the main participants of the inflammatory process. Therefore, moderate intervention in microglial activation may delay the progression of PD pathology $(44,45)$. As a result of the different surrounding microenvironments, microglia exhibit two different types of polarized phenotypes: Classic activation M1-like can promote inflammation and is associated with neurotoxicity, and choose activated M2-like is anti-inflammatory and can repair damage $(46,47)$. The present study data revealed that FMT treatment promoted the M2 polarization of microglia, and downregulated the expression of inflammatory factors, such as GSK $3 \beta$, IL- $1 \beta$, iNOS and TNF- $\alpha$.

The interaction between the brain and the intestines affects the behaviour of the host, and this effect mainly occurs through the sympathetic nerve, parasympathetic nerve branch of the autonomic nervous system and neuroendocrine nervous system (48). By activating the Toll-like receptor $4 / \mathrm{NF}-\kappa \mathrm{B}$ signalling pathway in the intestine to release proinflammatory factors, such as TNF- $\alpha$, it may induce the activation of intestinal immune cells, thereby releasing some inflammatory factors. Subsequently, glial cells enter the brain through the blood-brain barrier and induce neuroinflammation (49,50).

In summary, the present study provided evidence that FMT could reverse intestinal microbial dysfunction and lead to neuroprotection. However, whether this process reduces the activity of the TNF- $\alpha$, IL- $1 \beta$ and TGF- $\beta$ pathways in the intestine should be further studied. In addition, results of the present study revealed that treatment with FMT altered the expression levels of arginase, GSK3 $\beta$, IL-1 $\beta$, iNOS, p-PTEN and $\alpha 7 \mathrm{n}$ AchR; however, as inhibition, knockout or knockdown experiments were not explored, whether these changes may be attributed to FMT treatment require further investigation. Furthermore, the gene expression levels of TNF- $\alpha$, IL-1 $\beta$, IL-10 and TGF- $\beta$ were closely associated with FMT therapeutic effects, but whether these changes were caused by FMT treatment should be further discussed. Future research should look for other molecular markers that can be used in conjunction with information on intestinal microbial malnutrition, laying the foundation for the clinical promotion of FMT.

\section{Acknowledgements}

Not applicable.

\section{Funding}

The present study was supported by Hainan Provincial Natural Science Foundation of China (grant no. 818NQ316).

\section{Availability of data and materials}

All data generated or analysed during this study are included in this published article.

\section{Authors' contributions}

TZ and XC conceived the study and performed the methodology and investigation. TW performed the FMT experiments, analysed the gut microbiota data and wrote the original draft preparation.
$\mathrm{ZZ}$ performed the western blot experiments, analysed the data, and reviewed and edited the manuscript. ZC designed the experiments. All authors have read and approved the final manuscript. $\mathrm{TZ}$ and ZC confirm the authenticity of all the raw data.

\section{Ethics approval and consent to participate}

The research was approved by the Ethics Committee of the First Affiliated Hospital of Hainan Medical University (approval no. D-2017027).

\section{Patient consent for publication}

Not applicable.

\section{Competing interests}

The authors declare that they have no competing interests.

\section{References}

1. Takahashi J: Clinical trial for Parkinson's disease gets a green light in the US. Cell Stem Cell 28: 182-183, 2021.

2. Ding XB, Wang XX, Xia DH, Liu H, Tian HY, Fu Y, Chen YK, Qin C, Wang JQ, Xiang Z, et al: Impaired meningeal lymphatic drainage in patients with idiopathic Parkinson's disease. Nat Med 27: 411-418, 2021.

3. Zhang J, Perry G, Smith MA, Robertson D, Olson SJ, Graham DG and Montine TJ: Parkinson's disease is associated with oxidative damage to cytoplasmic DNA and RNA in substantia nigra neurons. Am J Pathol 154: 1423-1429, 1999.

4. Waters CM, Peck R, Rossor M, Reynolds GP and Hunt SP: Immunocytochemical studies on the basal ganglia and substantia nigra in Parkinson's disease and Huntington's chorea. Neuroscience 25: 419-438, 1988.

5. Crowther RA, Daniel SE and Goedert M: Characterisation of isolated $\alpha$-synuclein filaments from substantia nigra of Parkinson's disease brain. Neurosci Lett 292: 128-130, 2000.

6. Bhattarai Y, Si J, Pu M, Ross OA, McLean PJ, Till L, Moor W, Grover M, Kandimalla KK, Margolis KG, et al: Role of gut microbiota in regulating gastrointestinal dysfunction and motor symptoms in a mouse model of Parkinson's disease. Gut Microbes 13: 1866974, 2021.

7. Zhong XH, Haycock JW, Shannak K, Robitaille Y, Fratkin J, Koeppen AH, Hornykiewicz O and Kish SJ: Striatal dihydroxyphenylalanine decarboxylase and tyrosine hydroxylase protein in idiopathic Parkinson's disease and dominantly inherited olivopontocerebellar atrophy. Mov Disord 10: 10-17, 1995.

8. Zhong R, Chen Q, Zhang X, Li M and Lin W: Helicobacter pylori infection is associated with a poor response to levodopa in patients with Parkinson's disease: A systematic review and meta-analysis. J Neurol: Feb 22, 2021 (Epub ahead of print).

9. Schaeffer E, Vaterrodt T, Zaunbrecher L, Liepelt-Scarfone I, Emmert K, Roeben B, Elshehabi M, Hansen C, Becker S, Nussbaum S, et al: Effects of Levodopa on quality of sleep and nocturnal movements in Parkinson's Disease. J Neurol 268: 2506-2514, 2021.

10. Anwer S, Branchard E, Dan Q, Dan A and Szaszi K: Tumor necrosis factor- $\alpha$ induces claudin-3 upregulation in kidney tubular epithelial cells through $\mathrm{NF} \kappa \mathrm{B}$ and CREB1. Am J Physiol Cell Physiol 320: C495-C508, 2021.

11. Corbo RM, Businaro R and Scarabino D: Leukocyte telomere length and plasma interleukin-1 $\beta$ and interleukin-18 levels in mild cognitive impairment and Alzheimer's disease: New biomarkers for diagnosis and disease progression? Neural Regen Res 16: 1397-1398, 2021.

12. Carabotti M,Scirocco A, Maselli MA and Severi C: The gut-brain axis: Interactions between enteric microbiota, central and enteric nervous systems. Ann Gastroenterol 28: 203-209, 2015.

13. Cryan JF, O'Riordan KJ, Sandhu K, Peterson V and Dinan TG: The gut microbiome in neurological disorders. Lancet Neurol 19: 179-194, 2020. 
14. Shen L: Gut, oral and nasal microbiota and Parkinson's disease. Microb Cell Fact 19: 50, 2020.

15. Moustafa SA, Mohamed S, Dawood A, Azar J, Elmorsy E, Rizk NAM and Salama M: Gut brain axis: An insight into microbiota role in Parkinson's disease. Metab Brain Dis 36: $1545-1557,2021$.

16. Heintz-Buschart A, Pandey U, Wicke T, Sixel-Döring F, Janzen A, Sittig-Wiegand E, Trenkwalder C, Oertel WH, Mollenhauer B and Wilmes P: The nasal and gut microbiome in Parkinson's disease and idiopathic rapid eye movement sleep behavior disorder. Mov Disord 33: 88-98, 2018

17. Cirstea MS, Yu AC, GolzE, Sundvick K, KligerD, Radisavljevic N, Foulger LH, Mackenzie M, Huan T, Finlay BB, et al: Microbiota composition and metabolism are associated with gut function in Parkinson's disease. Movement Disord 35: 1208-1217 2020.

18. Zhang F, Cui B, He X, Nie Y, Wu K, Fan D, FMT-standardization Study Group: Microbiota transplantation: concept, methodology and strategy for its modernization. Protein Cell 9: 462-473, 2018

19. Xue LJ, Yang XZ, Tong Q, Shen P, Ma SJ, Wu SN, Zheng JL and Wang HG: Fecal microbiota transplantation therapy for Parkinson's disease: A preliminary study. Medicine (Baltimore) 99: e22035, 2020.

20. Zha Z, Lv Y, Tang H, Li T, Miao Y, Cheng J, Wang G, Tan Y, Zhu Y, Xing X, et al: An orally administered butyrate-releasing xylan derivative reduces inflammation in dextran sulphate sodium-induced murine colitis. Int J Biol Macromol 156: 1217-1233, 2020.

21. Wang $\mathrm{Y}$, Wei $\mathrm{N}$ and $\mathrm{Li} \mathrm{X}$ : Preclinical evidence and possible mechanisms of baicalein for rats and mice with Parkinson's disease A systematic review and meta-analysis. Front Aging Neurosci 12: 277,2020

22. Guo HM, Zhou ZY, Huang YQ, Li X and Wang XJ: Investigation of the roles of dysbindin-1 and SATB2 in the progression of Parkinson's disease. Eur Rev Med Pharmacol Sci 23: 7510-7516, 2019.

23. Li L, Chen Y, Tang J and Yuan L: Evaluation of efficiency omega 3 fatty acid improves the behavioural phenotype and protects against oxidative stress against $\mathrm{MPP}^{+}$induces Parkinson's disease in mice. Pak J Pharm Sci 34: 861-867, 2021.

24. Koentjoro B, Park J-S and Sue CM: Parkin western blotting is useful for identification of patients with Parkin-related Parkinson's disease. J Neurol Neurosurg Psychiatry 85: 1436-1437, 2014.

25. Oluwole OG, Kuivaniemi H, Abrahams S, Haylett WL, Vorster AA, van Heerden CJ, Kenyon CP, Tabb DL, Fawale MB, Sunmonu TA, et al: Targeted next-generation sequencing identifies novel variants in candidate genes for Parkinson's disease in Black South African and Nigerian patients. BMC Med Genet 21: 23, 2020

26. Illumina Inc.: $16 \mathrm{~S}$ Metagenomic Sequencing Library Preparation, 2013. https://support.illumina.com/content/dam/illumina-support/ documents/documentation/chemistry_documentation/16s/16smetagenomic-library-prep-guide-15044223-b.pdf. Accessed, April $15,2020$.

27. Livak KJ and Schmittgen TD: Analysis of relative gene expression data using real-time quantitative PCR and the 2(-Delta Delta C(T)) Method. Methods 25: 402-408, 2001.

28. Hamilton MJ, Weingarden AR, Sadowsky MJ and Khoruts A: Standardized frozen preparation for transplantation of fecal microbiota for recurrent Clostridium difficile infection. Am J Gastroenterol 107: 761-767, 2012.

29. Wlodarska M, Thaiss CA, Nowarski R, Henao-Mejia J, Zhang JP, Brown EM, Frankel G, Levy M, Katz MN, Philbrick WM, et al: NLRP6 inflammasome orchestrates the colonic host-microbial interface by regulating goblet cell mucus secretion. Cell 156 $1045-1059,2014$

30. Zhang L, Zhang L, Li Y, Li L, Melchiorsen JU, Rosenkilde M and Hölscher C: The novel dual GLP-1/GIP receptor agonist DA-CH5 is superior to single GLP-1 receptor agonists in the MPTP model of Parkinson's disease. J Parkinsons Dis 10: 523-542, 2020.

31. Li W, Wu X, Hu X, Wang T, Liang S, Duan Y, Jin F and Qin B: Structural changes of gut microbiota in Parkinson's disease and its correlation with clinical features. Sci China Life Sci 60: 1223-1233, 2017.

32. Bedarf JR, Hildebrand F, Coelho LP, Sunagawa S, Bahram M, GoeserF, Bork P and Wüllner U: Functional implications of microbial and viral gut metagenome changes in early stage L-DOPA-nave Parkinson's disease patients. Genome Med 9: 39, 2017.
33. Hill-Burns EM, Debelius JW, Morton JT, Wissemann WT, Lewis MR, Wallen ZD, Peddada SD, Factor SA, Molho E, Zabetian CP, et al: Parkinson's disease and Parkinson's disease medications have distinct signatures of the gut microbiome. Mov Disord 32: 739-749, 2017

34. Zhou ZL, Jia XB, Sun MF, Zhu YL, Qiao CM, Zhang BP, Zhao LP, Yang Q, Cui C, Chen X, et al: Neuroprotection of fasting mimicking diet on MPTP-induced Parkinson's disease mice via gut microbiota and metabolites. Neurotherapeutics 16: 741-760, 2019.

35. Sun B-L, Li W-W, Wang J, Xu YL, Sun HL, Tian DY, Wang YJ and Yao XQ: Gut microbiota alteration and its time course in a tauopathy mouse model. J Alzheimers Dis 70: 399-412, 2019.

36. Nagalingam NA, Kao JY and Young VB: Microbial ecology of the murine gut associated with the development of dextran sodium sulfate-induced colitis. Inflamm Bowel Dis 17: 917-926, 2011.

37. Scheperjans F, Aho V, Pereira PAB, Koskinen K, Paulin L, Pekkonen E, Haapaniemi E, Kaakkola S, Eerola-Rautio J, Pohja M, et al: Gut microbiota are related to Parkinson's disease and clinical phenotype. Mov Disord 30: 350-358, 2015

38. Huang H, Xu H, Luo Q, He J, Li M, Chen H, Tang W, Nie Y and Zhou Y: Fecal microbiota transplantation to treat Parkinson's disease with constipation: A case report. Medicine (Baltimore) 98: e16163, 2019.

39. Dutta SK, Verma S, Jain V, Surapaneni BK, Vinayek R, Phillips L and Nair PP: Parkinson's disease: The emerging role of gut dysbiosis, antibiotics, probiotics, and fecal microbiota transplantation. J Neurogastroenterol Motil 25: 363-376, 2019.

40. Lubomski M, Tan AH, Lim SY, Holmes AJ, Davis RL and Sue CM: Parkinson's disease and the gastrointestinal microbiome. J Neurol 267: 2507-2523, 2020.

41. Haavik $\mathbf{J}$ and Toska K: Tyrosine hydroxylase and Parkinson's disease. Mol Neurobiol 16: 285-309, 1998.

42. Kitamura Y, Sakanashi M, Ozawa A, Saeki Y, Nakamura A, Hara Y, Saeki KI and Arimoto-Kobayashi S: Protective effect of Actinidia arguta in MPTP-induced Parkinson's disease model mice. Biochem Biophys Res Commun 555: 154-159, 2021.

43. da Silva WAB, Ferreira Oliveira K, Caroline Vitorino L, Ferreira Romão L, Allodi S and Lourenco Correa C: Physical exercise increases the production of tyrosine hydroxylase and CDNF in the spinal cord of a Parkinson's disease mouse model. Neurosci Lett 760: 136089, 2021

44. Wang Y, Li M, Song M, Xu X, Xiong J, Yang X, Tan J and Bai Y: Expression of OX40 ligand in microglia activated by IFN-gamma sustains a protective $\mathrm{CD}^{+}{ }^{+} \mathrm{T}$-cell response in vitro. Cell Immunol 251: 86-92, 2008.

45. Utz SG, See P, Mildenberger W, Thion MS, Silvin A, Lutz M, Ingelfinger F, Rayan NA, Lelios I, Buttgereit A, et al: Early fate defines microglia and non-parenchymal brain macrophage development. Cell 181: 557-573.e18, 2020.

46. Kam TI, Hinkle JT, Dawson TM and Dawson VL: Microglia and astrocyte dysfunction in parkinson's disease. Neurobiol Dis 144: 105028,2020

47. Joers V, Masilamoni G, Kempf D, Weiss AR, Rotterman TM, Murray B, Yalcin-Cakmakli G, Voll RJ, Goodman MM, Howell L, et al: Microglia, inflammation and gut microbiota responses in a progressive monkey model of Parkinson's disease: A case series. Neurobiol Dis 144: 105027, 2020.

48. Hefazi M, Patnaik MM, Hogan WJ, Litzow MR, Pardi DS and Khanna S: Safety and efficacy of fecal microbiota transplant for recurrent clostridium difficile infection in patients with cancer treated with cytotoxic chemotherapy: A single-institution retrospective case series. Mayo Clin Proc 92: 1617-1624, 2017.

49. Porcu F, Rubio A, Pérez-Hernández M and Gutiérrez-López MD Effect of intensive and repeated use of ethanol on the integrity of blood-brain barrier in mouse brain. Role of toll-like receptor 4 (TLR4). Basic Clin Pharmacol Toxicol 115: 41, 2014.

50. Cao L, Liu C, Wang F and Wang H: SIRT1 negatively regulates amyloid-beta-induced inflammation via the NF- $\kappa \mathrm{B}$ pathway. Braz J Med Biol Res 46: 659-669, 2013.

This work is licensed under a Creative Commons Attribution-NonCommercial-NoDerivatives 4.0 International (CC BY-NC-ND 4.0) License. 